\title{
THE LARGE NORMAL-FAULTING MARIANA EARTHQUAKE OF APRI 5, 1990 IN UNCOUPLED SUBDUCTION ZONE
}

\author{
Yasuhiro Yoshida $^{1}$, Kenji Satake ${ }^{2}$ and Katsuyuki Abe ${ }^{1}$
}

Abstract. A large, $\mathrm{M}_{\mathrm{S}}=7.5$, shallow earthquake occurred beneath the Mariana trench on April 5, 1990. From the relocated aftershock distribution, the fault area is estimated to be $70 \times 40 \mathrm{~km}^{2}$. A tsunami observed on the Japanese islands verifies that the depth of the main shock is shallow. For waveform analysis, we use long-period surface waves and body waves recorded at global networks of GDSN, IRIS, GEOSCOPE and ERIOS. The centroid moment tensor (CMT) solution from surface waves indicates normal faulting on a fault whose strike is parallel to the local axis of the Mariana trench, with the tension axis perpendicular to it. The seismic moment is $1.4 \times 10^{20} \mathrm{Nm}$ ( $\mathrm{x} 10^{27}$ dyn.cm) which gives $\mathrm{M}_{\mathrm{w}}=$ 7.3. Far-field $P$ and $\mathrm{SH}$ waves from 13 stations are used to determine the source time function. Since the sea around the epicentral region is about $5 \mathrm{~km}$ deep, body waveforms are contaminated with water reverberations. The inversion results in a source time function with a predominantly single event with a duration of $10 \mathrm{sec}$, a seismic moment of $2.1 \times 10^{20}$ $\mathrm{Nm}$, and a focal mechanism given by strike $=198^{\circ}, \mathrm{dip}=48^{\circ}$, slip $=90^{\circ}$. The short duration indicates a small area of the npture. The location of the main shock with respect to the aftershock area suggests that the nodal plane dipping to the west is preferred for the fault plane. The local stress drop of the single subevent is estimated to be $150 \mathrm{MPa}$ (1.5 Kbars). The Mariana earthquake is considered to have occurred in an uncoupled region, in response to the gravitational pull caused by the downgoing Pacific plate.

\section{Introduction}

A large shallow earthquake occurred on April 5, 1990 just beneath the Mariana trench where the Pacific plate is subducting beneath the Philippine Sea plate. This is the largest shallow event ever recorded in the region; the last event with a similar magnitude was on September 22, 1902 with $M_{S}=7.5$ [Abe and Noguchi, 1983]. Since that event is very old for studying the focal mechanism, the 1990 Mariana earthquake provides us with a good opportunity to study the seismotectonic characteristics of this region. In this paper, we analyze waveform data to estimate the source process. This earthquake also caused a tsunami that was observed on the Japanese islands as well as the Pacific islands. The unusual behavior of the tsunami and the implication for hazard assessments of tsunami potential is described elsewhere [Satake et al., 1992].

IEarthquake Research Institute, University of Tokyo
2Department of Geological Sciences, University of Michigan

Copyright 1992 by the American Geophysical Union.

Paper number 92GL000165

0094-8534/92/92GL-00165\$03.00
The epicentral data suggest that the Mariana earthquake is an outer rise earthquake which is defined as an earthquake originated within the subducting plate in the vicinity of the trench axis. In the Mariana region, the Pacific plate is aseismically subducting beneath the Philippine Sea plate without causing large underthrusting earthquakes at the plate interface. This results from the weak coupling between the downgoing and overlying plates. In such uncoupled subduction zones, the outer rise earthquakes generally possess normal-fault type mechanisms with their tensional stress axes nearly perpendicular to the trench strike [Christensen and Ruff, 1988]. It is very intriguing whether the Mariana earthquake is one of such tensional outer-rise events in an uncoupled subduction zone.

\section{Main Shock and Aftershocks}

The hypocenter parameters of the 1990 Mariana earthquake given by NEIC are: origin time $21: 12: 35.5$ on April 5 (UT), epicenter $15.125^{\circ} \mathrm{N}, 147.596^{\circ} \mathrm{E}$, depth $11 \mathrm{~km}$, and $M_{s}$ 7.5. The location of the main shock is shown in Figure 1 with the 3-day aftershock distribution. The main shock is located just beneath the trench axis. An accurate estimate of focal depth from teleseismic data is generally difficult and the focal depth of the main shock was constrained to be $11 \mathrm{~km}$ by NEIC. The following analysis of surface and body waves supports this shallow origin. The T-phase was clearly recorded at Chichijima Island, $1400 \mathrm{~km}$ from the epicenter, and this observation is consistent with the shallow origin.

The NEIC locations of aftershocks extend as long as 70 $\mathrm{km}$ along the trench and the depth down to $46 \mathrm{~km}$ that is determined from depth phases. For more reliable locations, we applied a master event relocation method for arrival time data from common stations. The largest aftershock is selected as a

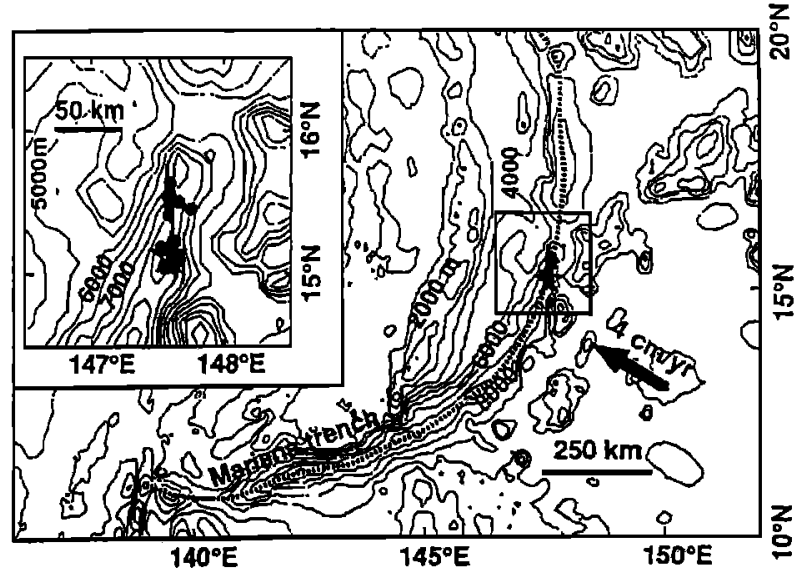

Fig. 1. Map of the source area. Star symbol denotes the main shock and circles denote the 3-day aftershocks. Data are from NEIC. Dotted line shows the trench axis. Bathymetric contours are also shown. Inset shows relocated epicenters and triangle denotes the master event used for relocation. 
master event. It occurred at 14:57:20.1 (UT) on April $6\left(\mathrm{~m}_{b}=\right.$ 5.9) near the southerm end of the aftershock area. The results were almost same as the NEIC locations (Figure 1). The length of the aftershock area is a little shorter, about $65 \mathrm{~km}$. The aftershocks are distributed in the N-S direction with a sparse region in the central part. The main shock is located in the southern cluster. Almost the same distribution is obtained for a master event near the northern end. This pattern of the aftershock activity suggests an inhomogeneous distribution of stress drop or strength on the fault plane.

The $\mathrm{pP}$ phases were reported on NEIC for 14 aftershocks. The pP-P times range from 10 to $15 \mathrm{sec}$. Since the sea depth in the epicentral area is $5 \mathrm{~km}$ or so, it is probable that pwP phases were misread to PP phases. We consulted seismograms recorded at Dodaira Micro-earthquake Observatory and its satellite stations at Kanto area in Japan. The epicentral distances are about $25^{\circ}$. Clear phases are observed 10 to $15 \mathrm{sec}$ after the $P$ wave amival. For example, the event of the 22:52:59.9 (UT) on April 5 shows clear phases 4 and $13 \mathrm{sec}$ after the $P$ wave arrival. If we assume that the thickness of the water layer as $5 \mathrm{~km}$ and the source depth as $25 \mathrm{~km}$, the phases arriving 4 and $13 \mathrm{sec}$ after $\mathrm{P}$ wave correspond to $\mathrm{pP}$ and $\mathrm{pwP}$ phase, respectively. This suggests that the $\mathrm{pP}$ phases reported by NEIC are pwP phases. This misreading results in overestimation of the focal depth. We calculated the source depth using the pP-P times of NEIC by assuming that the phases are pwP and got the depth range of 12 to $34 \mathrm{~km}$ for 12 aftershocks with an average of $23 \mathrm{~km}$ and a standard deviation of 6 $\mathrm{km}$. The fault width is estimated to be $40 \mathrm{~km}$ when the fault dip is $42^{\circ}$ which is derived from following body wave analysis.

\section{Surface Wave Analysis}

We performed a Centroid Moment Tensor (CMT) inversion [Dziewonski et al., 1981; Kawakatsu, 1989] using long-period surface waveforms (mainly R1 and G1) recorded at 19 stations of the IRIS, GDSN GEOSCOPE [Romanowicz et al., 1984] and ERIOS [Takano et al., 1990] networks. The stations used were COL, HRV, BCAO, CAY, COR, SCZ, PAS, KIP, PPT, CTAO, SLR, CMB, KEV, KMI, SSB, INU, MAJO, KONO and TSK. The data were deconvolved to displacements and bandpass filtered between the frequency range from 3 to $7 \mathrm{mHz}$. Combining the data from these stations, we have a good azimuthal coverage.

The final solution for the moment tensor elements is given in Table 1. The centroid location is $15.288^{\circ} \mathrm{N}$ and $147.397^{\circ} \mathrm{E}$ for a depth of $10 \mathrm{~km}$. The inversions were performed for the selective depths of 10,20 and $33 \mathrm{~km}$. The smallest variance of the solution was obtained for the depth of $10-20 \mathrm{~km}$. The nondouble-couple component that is expressed as the ratio of the minimum eigenvalue to the maximum is only $8 \%$ and negligibly small. The moment of the best double couple is $1.4 \mathrm{x}$ $10^{20} \mathrm{Nm}$ which gives $M_{w}=7.3$. The best double couple indicates almost pure normal-faulting with the strike almost paralIel to the local trench axis. The tensional axis is perpendicular to the trench and the compressional axis is almost vertical. These stresses are typical of outer rise normal fault events. The dip of the westward dipping plane is $30^{\circ}$. Though the solution is very similar to that obtained by Harvard and GEOSCOPE groups, the uncertainty is not small because of difficulty in determining the dip angle for shallow events. We
TABLE 1. Centroid moment tensor solution

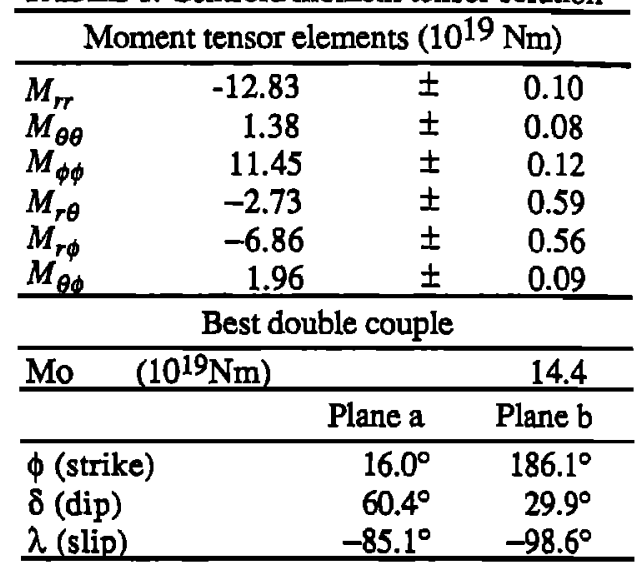

will get a steeper dip from the following analysis of body waves.

\section{Body Wave Analysis}

For body wave analysis, we used $\mathrm{P}$ and $\mathrm{SH}$ waves recorded at 13 stations at epicentral distances ranging from $30^{\circ}$ to $100^{\circ}$. The arrival times were read directly on the broadband channel. All the records were deconvolved to displacements.

We applied a multiple deconvolution method developed by Kikuchi and Kanamori [1991]. By minimizing the difference between the observed and synthetic waveforms, we determined the mechanisms of subevents. For the computation of Green's functions, we assumed a structure consisting of a water layer $5 \mathrm{~km}$ thick and an oceanic crust $10 \mathrm{~km}$ thick near the source region.

We computed Green's functions by assuming source depths of $6,10,14,16,20,25$ and $30 \mathrm{~km}$, and derived source mechanism for each depth with a source time function of triangular shape. The residual error was minimized for the case of $16 \mathrm{~km}$. Fixing the depth at $16 \mathrm{~km}$ and using a point source with the same mechanism as that obtained from the above analysis, we first made only one iteration. The seismic moment is obtained to be $2.1 \times 10^{20} \mathrm{Nm}$. The source time function is shown in Figure 2 (a) and the synthetic waveforms are shown in Figure 3. They show water reverberation similar to the observation, although the details are different. The difference may be due to our simplified water layer (uniform depth) or due to real complexity of the source process. If the latter case is true, more iterations should reveal the complex source process. We made five iterations. The seismic moment is obtained to be $3.0 \times 10^{20} \mathrm{Nm}$. Figure 2 (b) shows the a)

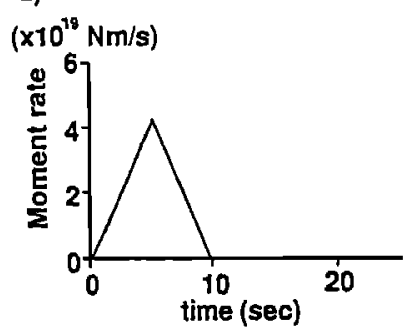

b)

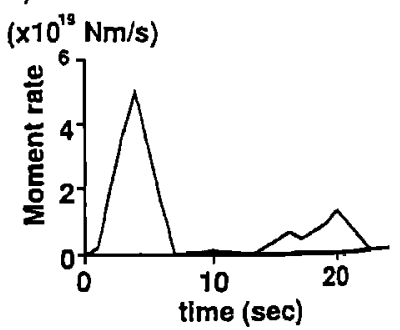

Fig. 2. Source time function for single event model (a) and five subevents model (b). 


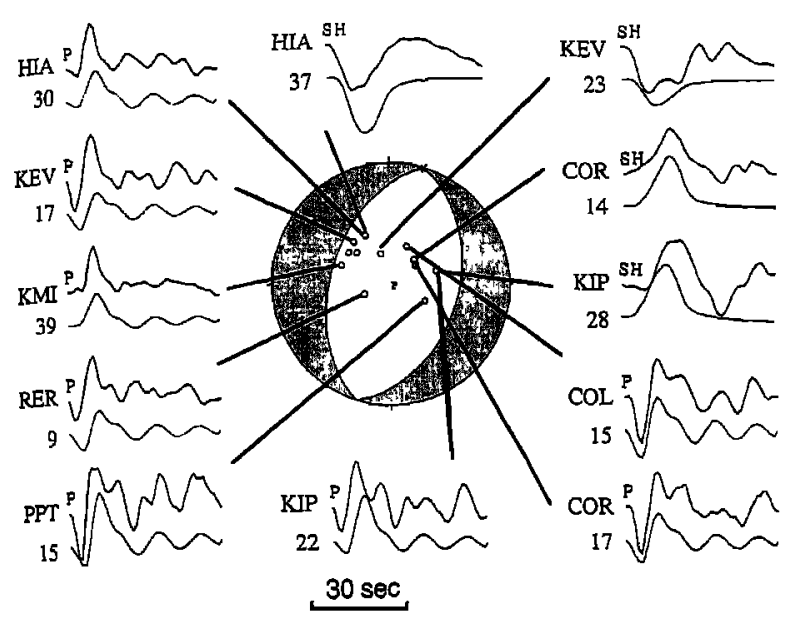

Fig. 3. Focal mechanism and body waves. The top and bottom traces are the observed and synthetic $P$ and $\mathrm{SH}$ waves, respectively. All the records show ground motion displacements. Focal mechanism solution from body wave analysis is plotted on lower hemisphere of focal sphere. Compressional quadrants are shaded. Seismograms are labeled with station names and maximum amplitude for each trace in $\mu \mathrm{m}$.

source time function. Residual reduction ( $49 \%$ ) is not significantly different from that of the single event $(53 \%)$ and it cannot be determined whether the source process is complex or not. The seismic moment from the single event is closer to that from the surface wave analysis. We prefer the single event solution for simplicity. The final source parameters are: strike $=197.5^{\circ}, \operatorname{dip}=47.8^{\circ}, \operatorname{slip}=90.2^{\circ} ;$ strike $=17.2^{\circ}, \operatorname{dip}=$ $42.2^{\circ}$, slip $=-90.2^{\circ}$. The mechanism is pure normal failting.

\section{Stress Drop}

We can derive the stress drop $\Delta \sigma$ for the largest subevent from the seismic moment $m$ and duration $2 \tau$. In the present model, the source time function of triangular shape is assumed, and half the duration $\tau$ corresponds to the rise time of

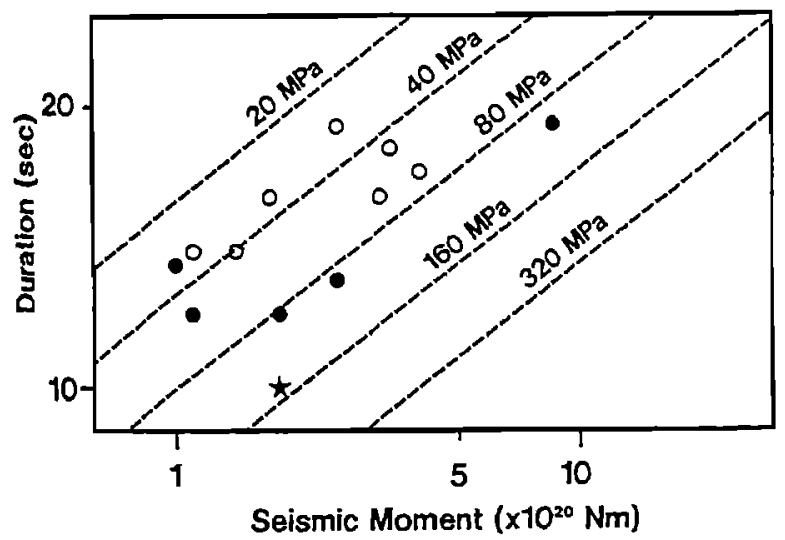

Fig. 4. Relation between duration and seismic moment of the largest subevent of major shocks of the world. Open circles represent interplate earthquakes [Kikuchi and Fukao, 1977], closed circles represent intraplate normal-faulting earthquakes [Sugi et al., 1987] and star symbol represents the 1990 Mariana earthquake. Dotted lines gives the relation of constant stress drops.
5 sec. We call $\Delta \sigma$ a local stress drop to distinguish it from an average stress drop over the entire fault. The local stress drop is estimated by the relation $\Delta \sigma=2.5 \mathrm{~m} /(\mathrm{v} \tau)^{3}$ where $m$ is the moment and $\mathrm{v}$ is the rupture velocity [Fukao and Kikuchi, 1987]. Using $\mathrm{v}=3.0 \mathrm{~km} / \mathrm{s}$, as was used by Fukao and Kikuchi [1987], we obtain $\Delta \sigma=150 \mathrm{MPa}$ (1.5 Kbars) for $\tau=$ $5 \mathrm{sec}$ and $m=2.1 \times 10^{20} \mathrm{Nm}$. This stress drop is much higher than the average stress drop of $3.2 \mathrm{MPa}$ over the fault plane of $70 \times 40 \mathrm{~km}^{2}$.

Figure 4 shows the relation between the duration and seismic moment of the largest subevent in large shallow earthquakes of the world. The data are taken from Kikuchi and Fukao [1987] for interplate thrust events and Sugi et al. [1987] for intraplate normal-faulting events. It is indicated that the local stress drop for intraplate earthquakes is one order of magnitude higher than that for interplate earthquakes. Sugi et al. [1987] interpreted this in terms of different nature of fault interface. The Mariana event shows the highest value among the intraplate shocks. This suggests that the Mariana earthquake was caused by rupture of almost intact material.

\section{Discussion and Conclusion}

In the Mariana region, the Pacific plate is subducting northwestwardly beneath the Philippine Sea plate. The seismicity indicates that the slab is subducting vertically. The deepest depth of the trench in the world and the steepest dip of the Wadati-Benioff zone are the characteristic feature of the Mariana region. At the Mariana trench, the convergence rate is as low as $4 \mathrm{~cm} /$ year [Seno, 1977], and the age of the subducting slab is very old, about $150 \mathrm{Ma}$ [e.g. Ruff and Kanamori, 1980]. Uyeda and Kanamori [1979] categorize these characteristics as an extreme end of the evolution of the subduction process.

There are two types of stresses which may be important in the origin of the outer rise normal-faulting earthquakes. One is caused by lithospheric flexure [e.g. Chapple and Forsyth, 1979] and the other is caused by gravitational pull from the subducting lithosphere [e.g. Kanamori, 1971]. The flexure model suggests that the outer rise events rupture by tensile stresses in response to the upward bending of oceanic plate near the trench. The gravitational pull model suggests that tensile stresses are transferred from the subducting plate directly to the outer rise due to the uncoupled nature of the plate boundary [Christensen and Ruff, 1988]. From the depth extent and the seismic moment, we cannot judge which model is preferable. In view of the location and size, however, we interpret the Mariana event as due to the gravitational pull.

It is well known that the 1933 Sanriku [Kanamori, 1971], the March 30, 1965 Rat Island $\left[\mathrm{M}_{\mathrm{w}}=7.5\right.$; Abe, 1972; Beck and Christensen, 1991] and the 1977 Sumba $\left[M_{w}=8.2-8.3\right.$; Spence, 1986; Spence, 1987; Lynnes and Lay, 1988] earthquakes occurred in the brittle part of the oceanic lithosphere in response to the pull of the subducting slab. Both the 1933 Sanriku and the March, 1965 Rat Island earthquakes occurred in subduction zones where the seismic coupling is intermediate to strong and underthrusting events with similar size or larger occur. These earthquakes took place in a spatial or temporal transition stage of the stress regime in the nearby plate boundaries [Christensen and Ruff, 1988]. On the other hand, the Mariana region is a typical uncoupled subduction zone. According to Ruff and Kanamori [1980] and Peterson 
and Seno [1984], the subducting and overlying plates in the Mariana region are purely uncoupled, that is, the Pacific plate is subducting aseismically without causing large underthrusting earthquakes. There is no evidence of a similar size or larger underthrusting event during historic times. The 1977 Sumba earthquake is another example of an outer rise normal faulting event in an uncoupled region. It is the largest earthquake in the Sunda arc ever recorded. These show that the largest earthquakes in the uncoupled zone are outer rise normal fault events.

The shallow Mariana earthquake of 1990 occurred beneath the Mariana trench where the Pacific plate is aseismically subducting. Waveform analyses and aftershock distribution reveal that this event represents pure normal faulting on a fault with strike $=197.5^{\circ}$, dip $=47.8^{\circ}$ and slip $=90.2^{\circ}$. The seismic moment is $2.1 \times 10^{20} \mathrm{Nm}$. The duration of the rupture is $10 \mathrm{sec}$ and the local stress drop is as high as $150 \mathrm{MPa}$. The Mariana earthquake is considered to have occurred in the uncoupled region, in response to the gravitational pull caused by the downgoing Pacific plate.

Acknowledgments. We thank Barbara Romanowicz for sending us the GEOSCOPE data, staff in IRIS DMC for sending us the IRIS data, staff in JMA for Chichijima seismogram and Taku Urabe for showing us the data of Dodaira Micro-earthquake Observatory. We also thank Larry Ruff, Doug Christensen and Roland LaForge for reading the manuscript and giving us valuable comments.

\section{References}

Abe, K., Lithospheric normal faulting beneath the Aleutian trench, Phys. Earth Planet. Inter., 5, 190-198, 1972.

Abe, K. and S. Noguchi, Revision of magnitudes of large shallow earthquakes, 1897-1912, Phys. Earth Planet. Inter., 33, 1-11, 1983.

Beck, L. S. and D. H. Christensen, Rupture process of the February 4, 1965, Rat Islands earthquake, J. Geophys. Res., 96, 2205-2221, 1991.

Chapple, W. M. and D. W. Forsyth, Earthquake and bending of plates at trenches, J. Geophys. Res., 84, 6729-6749, 1979.

Christensen, D. H. and L. Ruff, Seismic coupling and outer rise earthquakes, J. Geophys. Res., 13, 13421-13444, 1988.

Dziewonski, A. M., T.-A. Chou and J. H. Woodhouse, Determination of earthquake source parameters from waveform data for studies of global and regional seismicity, J. Geophys. Res., 86, 2825-2852, 1981.

Fukao, Y. and M. Kikuchi, Source retrieval for mantle earthquakes by iterative deconvolution of long-period $\mathrm{P}$ waves, Tectonophysics., 144, 249-269, 1987.

Kanamori, H., Seismological evidence for a lithospheric normal faulting - The Sanriku earthquake of 1933, Phys. Earth Planet. Inter., 4, 289-300, 1971.
Kawakatsu, H., Centroid single force inversion of seismic waves generated by landslides, J. Geophys. Res., 94, 12363-12374, 1989.

Kikuchi M. and Y. Fukao, Inversion of long-period $P$ waves from great earthquakes along subduction zones, Tectonophysics, 144, 231-247, 1987.

Kikuchi, M. and H. Kanamori, Inversion of complex body waves - III, Bull. Seism. Soc. Am., in press, 1991.

Lynnes, C. S. and T. Lay, Source process of the great 1977 Sumba earthquake, J. Geophys. Res., 93, 13407-13420, 1988.

Peterson, E. T. and T. Seno, Factors affecting seismic moment release rates in subduction zones, $J$. Geophys. Res., 89, 10233-10248, 1984.

Romanowicz, B., M. Cara, J. F. Fels and D. Rouland, GEOSCOPE: A French initiative in long-period threecomponent global seismic networks, EOS Trans. AGU, 65, 753-754, 1984.

Ruff, L. and H. Kanamori, Seismicity and the subduction process, Phys. Earth Planet. Inter., 23, 240-252, 1980.

Satake, K., Y. Yoshida and K. Abe, Tsunamis from the Mariana earthquake of April 5, 1990: its abnormal propagation and implication to tsunami potential from outerrise earthquakes, Geophys. Res. Lett., this issue, 1992.

Seno, T. The instantaneous rotation vector of the Philippine Sea plate relative to the Eurasian plate, Tectonophys., 42 , 209-226, 1977.

Spence, W., The 1977 Sumba earthquake series: Evidence for slab pull force acting at a subduction zone, J. Geophys. Res., 91, 7225-7239, 1986.

Spence, W., Slab pull and the seismotectonics of subducting lithosphere, Rev. Geophys., 25, 55-69, 1987.

Sugi, N., M. Kikuchi and Y. Fukao, Large shallow earthquakes of normal fault type within a subducting oceanic plate (in Japanese). Programme and Abstracts, Annual Meeting, Seismol. Soc. Jpn., No.1, 241, 1987.

Takano, K., M. Takeo, K. Abe, S. Tsuboi and M. Takahashi, The automated data acquisition system for the remote digital broadband seismographs (abstract), EOS Trans. AGU, 71, 899, 1990.

Uyeda, S. and H. Kanamori, Back arc opening and the mode of subduction, J. Geophys. Res., 84, 1049-1061, 1979.

K. Abe and Y. Yoshida, Earthquake Research Institure, University of Tokyo, Yayoi, Bunkyo-ku, Tokyo, 113 Japan.

K. Satake, Department of Geological Science, University of Michigan, 1006 C. C. Little Building, Ann Arbor, MI 48109 .

(Recieved August 27, 1991; revised December 3, 1991; accepted December 4, 1991) 